\title{
The role of safety management system in safety culture in an oil and gas exploration and production company in Asalouyeh, Bushehr Province, Iran, in2015
}

\author{
Afroghi SA, $\mathrm{MSc}^{1}$, Mirzaei $\mathrm{R}, \mathrm{PhD}^{2 *}$, Nasrabadi $\mathrm{M}, \mathrm{PhD}^{1}$ \\ 1- Faculty Member, Dept. of HSE, Faculty of Humanity, Islamic Azad University, Zahedan Branch, Zahedan, Iran. 2- Associate Prof., \\ Health Promotion Research Center, Health School, Zahedan University of Medical Sciences, Zahedan, Iran.
}

\begin{abstract}
Received: August 2015, Accepted: October 2015

Background: One of the necessities of industrial societies is the application of developed measures/strategies for the prevention of occupational incidents in industrial companies. The present study was conducted with the aim of determining the role of the safety management system on safety culture of an oil and gas exploration and production company.

Materials and Methods: This study was conducted on 240 participants, chosen through simple random sampling, based on the research goals, statistical society size, and the Krejcie and Morgan table. For data collection, the Safety Management System Questionnaire, with a Cronbach's $\alpha$ of 0.96, and the Safety Culture Questionnaire, with a Cronbach's $\alpha$ of 0.91 , were utilized after determining their validity. The gathered data were analyzed using SPSS and LISREL softwares.

Results: First level confirmatory factor analysis was performed with the use of LISREL package on 5 factors of encouraging/motivating employees to observe safety tips, educating employees on safety tips, safety policies in organizations, safety control in organizations, and urgent planning in organizations. The results showed that all the indices on obtained values were very desirable. In addition, the results of this research indicated that there was a statistically positive, meaningful relationship between the variable of safety management system and its components (i.e., safety policies, employees' motivators, safety education, urgent prevention plans, and internal control), and safety culture $(\mathrm{P}<0.01)$. High education levels of the employees had meaningful impacts on the safety management system $(\mathrm{P}<0.01)$.However, there was no statistically significant relationship between the education level and occupational background of the employees and the company's safety culture $(\mathrm{P}>0.05)$.

Conclusions: The results of the present paper proved that the safety management system and its components play an important role in the development of the safety culture of an oil company. Therefore, notifying the related authorities of this fact in order to establish a safety management system is a vital issue.
\end{abstract}

Keywords: Employees, Safety, Education, Prevention and Control, Safety Management.

\section{Introduction}

A workforce-related problem that different organizations in different countries currently face is the high rate of financial damages and casualties. For example, in 2005, Spain's Service Center reported an alarmingly high rate of incidents, the total cost of which was extremely high (1). As the figures demonstrate, 68 out of 1000 persons in the manufacture industry of Hong Kong and 9 out of 1000 persons in Singapore have an accident (2).

According to the International Labour Organization (ILO), 120 million occupational incidents occur each year, causing death of and

\footnotetext{
Corresponding author: Ramazan Mirzaei, Health Promotion Research Center, Health School, Zahedan University of Medical Sciences, Zahedan, Iran.

Email: rammir277@gmail.com,
} 
injuries to 210 thousand people (3).Evidently, such casualties are followed by heavy damages for organizations/companies (3).

Undeniably, developed strategies are required to prevent accidents and incidents in industrial companies. In recent decades, organizations have attempted to remove and reduce casualties through focusing on creating a safety culture. The term safety culture was initially used in 1987 in the notification of the International Atomic Energy Agency (IAEA) on the explosion of Chernobyl (4).Since then it has been incrementally used in the context of various organizations.

Reason believes that safety culture is an informative culture that everyone knows and does not exceed its limits (5).A crucial matter about safety culture is the matter of its definition which has not been specified thus far. The aim of safety culture, as a set of beliefs, norms, motives, roles, and technical-social practices that reduce the exposure of employees, managers, consumers, and the general public to dangerous and deleterious conditions, is to create an atmosphere in which workers become familiar with dangers and avoid unsafe actions (6).

Creating a safety culture in an organization reduces the rate of occupational incidents, concentrates on the safety issue, signifies that the organization's members share their opinions about the dangers, increases the members' commitment to safety, and determines the benefit level of safety programs (4).In such an organization, a positive safety culture with features like dialogue based on mutual trust, common understanding of the importance of safety, and trusting the efficacy of actions always exists (7).

Reason believes that an efficient safety culture is based on the three components of report culture, culture, and learning culture for the creation of which a safety database system is essential (5).This system requires the involvement of the employees of that organization to make it influential (5). He explained that the organization's workers are ready to report their own mistakes. The organization has to have a single culture to differentiate desirable and undesirable activities from one another (8).

Eventually, the dominance of the learning culture is essentially demanded for developing a safety culture. It is said that the two variables of safety culture and safety management culture have major impacts on safety behavior and the rate of occupation a incidents $(9,10)$.

The safety management system is the basis for understanding dangers in one's organization (11) and results in high safety levels and low expenses (12). This safety management system basically includes strategies and policies which creates effective relationships in the higher levels of an organization's hierarchy.

Safety management should specify the probable dangers of industrial machinery in a specific period of time. Moreover, danger analysis and safety engineering are considered as important activities in safety management. Danger analysis is the evaluation of different types of dangers, and safety engineering focuses on turning unacceptable dangers into acceptable threats (13).

It is completely understandable that every single occupational incident, disease, and environmental harm causes many heavy, direct and indirect damages to the organizations. Instances, like India's Bhopal, the Soviet Union's Chernobyl, the accident of Felix borough in England, and Iran's Neyshabour train accident, confirm such a claim (14).

Workforce is recognized as the most valuable asset in all countries around the world, determining different regions' productivity and economic growth, and the workers' behavior is the main obstacle for avoiding financial costs and casualties (15). Hence, this research was conducted with the aim of evaluating the safety management system, safety culture, and their relationship with each other among the workers 
of an oil and gas exploration and production company.

\section{Materials and Methods}

The present study was a field research.For measuring variables, the Safety Management System Questionnaire(1) and Safety Culture Questionnaire(16) were utilized. The Safety Management System Questionnaire had 5 subscales including safety policy, employees' motives, safety education, urgent prevention planning, and internal control. The questionnaire was scored based on a 5-pointLikert scale (option 1: strongly agree to option 5: strongly disagree). Since this was the first time that the Safety Management System Questionnaire was used in Iran, initially, the questionnaire was translated into Farsi by the researcher. Following this, in order to make sure of the accuracy of the translation, the text was reviewed by a professional translator and two specialists (supervisors and counselor) in this field. Eventually, final revisions were implemented based on the suggestions. The two questionnaires' features are reported in detail in the following sections.

The questionnaire's reliability was confirmed using Cronbach'salpha (0.89), and its validity has been confirmed using an exploratory and confirmatory factor analysis on 455 Spanish companies as sample(17). In this study, the validity of the questionnaire was calculated through factor analysis and confirmed by an expert panel and its reliability was estimated using Cronbach'salpha (0.91).

The Safety Culture Questionnaires designed by Alimohammadi et al. (16) was utilized for studying the safety culture variable. This questionnaire consists of 25 items and 5 subscales of management commitment, education and information exchange, supportive environment, obstacles, and prioritizing safety. The Cronbach'salpha of this tool equals 0.86 , and its validity has been confirmed using factor analysis.
In this research, the reliability of every component/factor of the two questionnaires was calculated using Cronbach'salpha and SPSS software (version 20, SPSS Inc., Chicago, IL, USA). Then, their validity was calculated using confirmatory factor analysis and LISREL software (version 8.72, SSI Inc., Lincolnwood, IL, USA). After extracting the factors of the Safety Culture Questionnaire, in order to understand whether the assigned variables for each factor measure it or not, first level confirmatory factor analysis was utilized. First level confirmatory factor analysis and LISREL software package were used for factors of encouraging employees to observe safety tips, educating the employees on safety tips, safety policy in organizations, safety control in organizations, and urgent planning in organizations. After checking and reviewing all the components of the safety management system with first level confirmatory factor analysis, second level factor analysis was performed to find out whether all these components couldbe placed in one single concept (i.e., safety policy) or not. Consequently, fitted indicators were resulted, and the graph of this analysis was drawn based on figure 1 . In the graph, ovals demonstrate hidden variables, and rectangles illustrate the items of the questionnaire. Furthermore, unidirectional arrows from ovals to rectangles indicate where the items are loaded, and the written values/figures on the arrows are the items' variances, describable by a hidden variable. Small arrows show the remaining variance (error), which cannot be explained by a hidden variable, and bilinear arrows show the correlation between the sub-questionnaires. As is noticeable in figure1, load factor of the five subquestionnaires (Policy, Encouragement, and etc.) ranges between 0.61 and 0.88 . This range suggests a favorable correlation between the items and the total number, and $\mathrm{t}$ amounts are meaningful for all standard coefficients of the significance level of 0.05 . 


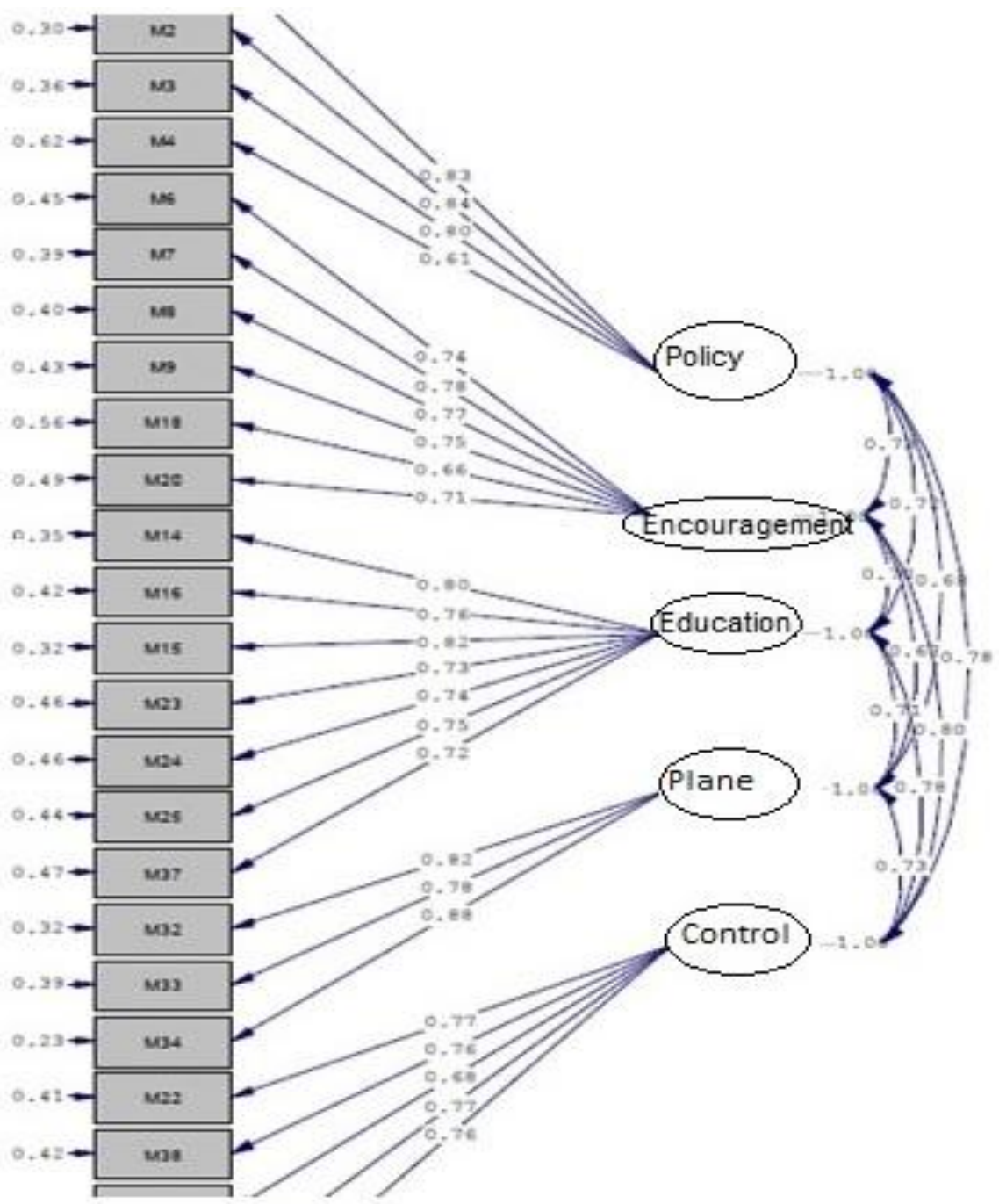

Figure1. A measuring model for the Safety Management System Questionnaire in the Standard Form (Policy stands for safety policy,encouragement stands for encouraging employees to observe safety tips,education stands for educating employees on safety tips,control stands for safety control in the organization, and plan in the figure means urgent planning in the organization.)

The statistical population of this research consisted of 2000 employees ofanoil and gas company located in Asalouyeh, in Southern Bushehr Province, Iran. Based on the research goals, the statistical population size, and the Krejcie and Morgan table, the sample size was calculated at 221 males. Thus, 250 questionnaires were distributed among the participants who were selected through simple random sampling. After data collection, statistical analyses were conducted.

For data analysis, descriptive (frequency and percentage estimation) and analytical (reliability and validity of the questionnaires, Pearson correlation coefficient, regression analysis, and one-way ANOVA for studying the variables) statistical methods were applied using SPSS and LISREL softwares. 


\section{Results}

The participants were divided into 4 groups of 21-30, 31-40, 41-50, and more than 50 years of age based on their age, and 3 groups of less than 10 years (frequency of 96, 40\%), 11-20 years (frequency of $87,36 \%$ ), and more than 20 years (frequency of 57, 23\%) based on their occupational background. The participants' education levels are shown in table 1 .

Table1: Education level of the participants

\begin{tabular}{llll}
\hline Row & Education level & Frequency & Percentage \\
\hline 1 & Diploma and associate of arts & 69 & 28 \\
\hline 2 & Bachelor of science & 102 & 42 \\
\hline 3 & Master of science and higher & 69 & 28 \\
\hline 4 & Total & 240 & 100 \\
\hline
\end{tabular}

First level confirmatory factor analysis was performed with LISREL package on 5 factors of encouraging the employees to observe safety tips, training the employees on safety tips, safety policy in organizations, safety control in organizations, and urgent planning in organizations. The results indicated that all the indices on the obtained values were very desirable and appropriate.

Moreover, the results revealed that there is a positive, meaningful relationship between the safety management system and its components (safety policy, employees' motives, safety education, urgent prevention programs, and internal control), and safety culture (Table 2) $(\mathrm{P}=0.01)$. Furthermore, high education levels have meaningful effects on the safety management system $(\mathrm{P}=0.01)$. Nevertheless, no statistically meaningful relationship was observed between the education level and occupational back ground of the employees, and the company's safety culture $(\mathrm{P}>0.05)$.

Table 2: Correlation between dependent and independent variables

\begin{tabular}{lllll}
\hline $\begin{array}{l}\text { Dependent } \\
\text { variable }\end{array}$ & Independent variable & $\begin{array}{l}\text { Correlation } \\
\text { coefficient }\end{array}$ & $\mathbf{r}$ & $\mathbf{P}$ \\
\hline \multirow{4}{*}{ Safety culture } & Safety policy & Pearson & 0.60 & 0.01 \\
\cline { 2 - 5 } & Employees' motives & Pearson & 0.52 & 0.01 \\
\cline { 2 - 5 } & Safety education & Pearson & 0.59 & 0.01 \\
\cline { 2 - 5 } & Urgent organizational planning & Pearson & 0.48 & 0.01 \\
\cline { 2 - 5 } & Organization's internal control & Pearson & 0.52 & 0.01 \\
\hline
\end{tabular}

\section{Discussion}

As the data analysis in this research showed, there is a positive and meaningful relationship between the safety management system and safety culture. In other words, if high quality structured polices and strategies are developed and executed in an organization or a company, the safety culture of that company or organization will increase. The safety culture is a form of culture that makes everyone committed to pay attention to the company's safety issues. This result is compatible with the results of other researches (18-22) concerning the impact of the safety management system on the dominance of safety in a company or organization and the close relationship between 
positive perspectives towards safety and the creation of safety culture in an organization.

According to the obtained results, the relationship between safety culture and safety policy became meaningful. Therefore, if the safety policies are organized to have positive influences on the perspective and behavior of the workers, their motivation, commitment, and knowledge of unsafe activities, positive and desirable culture-related consequences will be obtained. This has also been proven by other researches regarding the effect of safety policies of an organization on its safety issues $(23,24)$.

It has also been found that there is a meaningful relationship between safety culture and the workers' motives to observe safety rules; that is to say, provided that constant motivators (e.g., financial rewards) are present for the employees. Thus, the safety culture is developed, and everyone feels responsible for any harm and damage threatening the company/ organization through observing teamwork methods and safety rules, like accurate use of safety tools and consultation with the employees. This result is compatible with the findings of a study by Reimann et al., underscoring the role of motivation as a psychological factor, which is sometimes decreased due to external control and boring routine work, in the safety culture (25). This result is also in agreement with the results of a study by Vanerhaff, which acknowledged personal awareness/knowledge as the most crucial factor in safety management (26). The suggestions and guidelines provided in the abovementioned studies for designing more efficient facilities in addition to the methods for improving the employees' efficiency are similar and even harmonious with those of the present study.

The present research illustrated that there was a meaningful relationship between safety culture and safety education. Taghdisi et al., in a paper entitled "Effects of Education Interventions on the Coke workers' Immune Performances on
Baznef Model Basis at Isfahan Melting Factory", also exclaimed that the inferential role of education on the development of safety concept cannot be denied (27).

In addition, this study showed that there is a statistically meaningful relationship between safety culture and the organization's urgent plans. This has already been confirmed by the results of a study entitled "safer occupational environment: evaluation and determination of safe atmosphere's role" (28). The researchers of the mentioned study believed that there is a positive and meaningful relationship between the safety programs and policies of a company and the creation of a safe environment (28).

In this study, a meaningful difference was observed among the average job experiences of the employees in different levels in their tendency towards the safety management system. However, there was no meaningful difference among the average occupational back ground of the employees in the variables of safety culture and safety management system.

\section{Conclusion}

The results proved that, if the programs and activities of an organization are periodically reviewed, its incidents are recorded and reported, and appropriate external and internal evaluations of its components are performed, the safety culture of that organization willimprove. The safety management system and its components play an important role in the expansion and improvement of the safety culture. Therefore, educating authorities on creating an appropriate safety management system in oil and gas companies would be highly desirable and beneficial.

\section{Acknowledgment}

This project has been supported financially by the Islamic Azad University and the authorities of the oil and gas company. The researchers of 
this study would like to thank the authorities and all the participants in acknowledgement of their contribution.

Conflict of interest: None declared.

\section{References}

1. Fernandez-Muniz B, Montes-Peon JM, Vazquez-Ordas CJ. Safety management system: Development and validation of a multidimensional scale. J Loss Prev Process Ind 2007; 20(1):52-68.

2. Yng Ling FY, Liu M, Woo YC. Construction fatalities in Singapore. International Journal of Project Management 2009; 27(7):717-26.

3. Lourdes CO, Christine VG, Concepción MV, Evarista AG. Occupational risks and health: perceptions of indigenous female agricultural workers in Northwestern Mexico. Salud Colect 2013; 9(2):247-56.

4. Cooper D. Safety culture: A model for understanding and quantifying a difficult concept. Prof Saf 2002; 47(6):30-6.

5. Reason J. Safety paradoxes and safety culture. Inj Control Saf Promot 2000; 7(1):314.

6. Fernandez-Muniz B, Montes-Peon JM, Vazquez-Ordas CJ. Safety culture: Analysis of the causal relationships between its key dimensions. J Safety Res 2007; 38(6):627-41.

7. Cox SJ, Cheyne AJT. Assessing safety culture in offshore environments. Saf Sci 2000; 34:111-29.

8. Reason JT. Managing the Risks of Organizational Accidents. 1st ed. Aldershot, United Kingdom: Ashgate; 1997.

9. Flin R, Mearns K, O' Conner P, Bryden R. Measuring safety climate: identifying the common features. Saf Sci 2000; 34:177-92.

10. Mearns K, Whitaker S, Flin R, Gordon R, O'Connor P. Benchmarking human and organizational factors in offshoresafety. HSE OTO 2000; Report NO.:061. Available at: http://www.abdn.ac.uk/iprc/papers.Reports/V ol.201, 3-10 Benchmarking.Pdf.2006.

11. Johnson WB, Avers K. Return on Investment Tool for Assessing Safety Interventions. Paper presented at Shell Aircraft Safety Seminar 2012 Human Factors -Safety's Vital Ingredient; 2012 October 11-12; The Hague, Netherlands.
12. Mitchison N, Papadakis GA. Safety management system under Seveso II: Implementation and assessment. J Loss Prev Process Ind 1999; 12(1):43-51.

13. Wahlstrom B, Rollenhagen C. Safety management - A multi-level control problem. Saf Sci 2014; 69:3-17.

14. Kartam NA, Flood I, Koushki P. Construction safety in Kuwait: Issues, procedures, problems, and recommendations. Saf Sci 2000; 36(3):163-84.

15. Hofmann DA, Stetzer A. A cross-level investigation of factors influencing unsafe behaviours and accidents. Pers Psychol 1996; 49(2):307-39.

16. Alimohammadi I, Jahani-hashemi H, Farshad AA, Amini M, Haghi B, Nori $\mathrm{S}$, et al. Assessment of reliability of a safety culture questionnaire in the cleanser and washer industries. Journal of Health and Safety at Work 2012; 2(2):33-42.

17. Beatriz FM, José Manuel MP, Camilo José VO. Relation between occupational safety management and firm performance. Safety Science 2009; 47(7):980-91.

18. Grecco CHDS, Vidal MCR, Cosenza CAN, Santos IJALD, Carvalho PVRD. Safety culture assessment: A fuzzy model for improving safety performance in a radioactive installation. Progress in Nuclear Energy 2014; 70:71-83.

19. Cooper D. Toward a model of safety culture. Saf Sci 2000; 36:111-36.

20. Kennedy R, Kirwan B. Development of a hazard and operability-based method for identifying safety management vulnerabilities in high risk systems. Saf Sci 1998; 30(3):67-92.

21. Nielsen KJ. Improving safety culture through the health and safety organization: A case study. J Safety Res 2014; 48:7-17.

22. Halvani G, Ebrahimzadeh M, Dehghan M, Fallah H, Mortazavi M. Assessment of factors affecting safety culture in Yazd steel industry workers. Occupational Medicine Quarterly Journal 2012; 4(1-2):66-72.

23. Fernandez-Muniz B, Montes-Peon JM, Vazquez-Ordas CJ. Relation between occupational safety management and firm performance. Saf Sci 2009; 47(7):980-91.

24. Cheng EWL, Ryan N, Kelly S. Exploring the perceived influence of safety management practices on project performance in the 
construction industry. Saf Sci 2012; 50(2):363-9.

25. Reiman T, Pietikainen E, Kahlbom U, Rollenhagen C. Safety culture in the Finnish and Swedish nuclear industries - history and present. Denmark: Nordic nuclear safety research; 2010. 41(19):NKS-213.ISBN 97887-7893-282-2.

26. Vanderhof W. How to get workers to wear it. Occup Health Saf 2004; 73(12):42-4.

27. Taghdisi MH, Madadzadeh N, Shadzi SH,
Hasanzadeh A. Effects of Education Interventions on the Coke workers' Immune Performances on Baznef Model Basis at Isfahan Melting Factory, 2005. Jornal of Ilam University of Medical Sciences 2008; 16(3):20-30.

28. DeJoy DM, Schaffer BS, Wilson MG, Vandenberg RJ, Butts MM. Creating safer workplaces: assessing the determinants and role of safety climate. J Safety Res 2004; 35(1):81-90. 